\title{
Prevalence of Obesity and the Factors Influencing it among Women in a Slum of Mumbai
}

\author{
Dr. Tage Taka ${ }^{1}$, Dr. Ancilla Tragler ${ }^{2}$ \\ ${ }^{I}$ (Epidemiologist, National Programme for Prevention and Control of Cancer, Diabetes, Cardiovascular \\ Diseases and Stroke (NPCDCS), Govt. of Arunachal Pradesh, India) \\ ${ }_{2}^{2}$ (Community Health Coordinator Navjeet, Senior Pediatric Consultant, Bandra Holy Family Hospital, Mumbai, \\ India)
}

\begin{abstract}
:
Objective: The objective of the study was to find out the prevalence of obesity in women of a slum population in Mumbai. Various factors relating to obesity were also studied. Study design: Cross sectional community based study design with quantitative method. Material and Methods: 126 female respondents, 18 years and above, were selected in the study by systematic random sampling. Face to face interview was done using a semi structured interview schedule. Height, weight and waist circumference were measured and then Body Mass Index (BMI) and waist hip ratio (WHR) calculated. Results: There was a high incidence of overweight, (32.5\%) and obesity class I (20.6\%) and class II (6.3\%) were found in the study. Abdominal obesity was found in $57.1 \%$ of the respondents. Statistically significant values were found in the correlation of obesity and lack of physical activity, non-vegetarian diet and unemployment status. Conclusion: There is a high prevalence of obesity in this study of women in a slum of Mumbai. Correlating factors of obesity in this study were, lack of physical exercise, non-vegetarian diet and unemployment status. Interventions for obesity control were planned.
\end{abstract}

Keywords: Obesity, Overweight, BMI, Women, Slum population, Diet, Physical Exercise

\section{Introduction}

Globally, people now have a more sedentary kind of lifestyles due to various factors like industrialization, the ever growing IT sector, media growth and the rise in the economy. These consistent changes in the lifestyle and dietary patterns, causes fat accumulation in the body and in the long run leads to chronic diseases, like hypertension, diabetes and cardiovascular diseases.

Earlier overweight and obesity were universally accepted as a problem of the rich countries, but the scenario has changed in the present generation, as we can see a significant problem of overweight and obesity even in middle and low-income countries ${ }^{[1]}$. The epidemiological transition has shown the shift of diseases from communicable to non-communicable disease, such as cardiovascular disease, hypertension, diabetes and cancer ${ }^{[2]}$. Noncommunicable disease (NCDs) are the prominent health problems of both the developed and the developing countries, which includes the middle and lower income countries. Overweight and obesity have always been one of the major factors influencing such health problems. According to World Health Organization reports, NCDs are the leading cause of mortality in the world, representing over $60 \%$ of all deaths. Out of the 36 million people who died from NCDs in 2005, half were under age 70 and half were women. Of the 57 million global deaths in 2008, 63\% of total deaths worldwide were due to NCDs. By 2030, deaths due to chronic NCDs are expected to increase to 52 million per year, which is alarming ${ }^{[3]}$.

Overweight and obesity are the fifth leading risk for global deaths. Every year at least 2.8 million adults die due to overweight or obesity. In addition to this fact, $44 \%$ of the diabetes burden, $23 \%$ of the ischemic heart disease burden and between $7 \%$ and $41 \%$ of certain cancer burdens are attributable to overweight and obesity ${ }^{[3]}$.

The global age-standardized prevalence of obesity nearly doubled from $6.4 \%$ in 1980 to $12.0 \%$ in 2008 ${ }^{[4]}$. In 2008, more than 1.4 billion adults, 20 years and older, were overweight. Out of these more than 200 million men and nearly 300 million women were obese. $65 \%$ of the world's population, live in countries where overweight and obesity kills more people than underweight ${ }^{[3]}$. In 2011 , more than 40 million under five children were overweight ${ }^{[3]}$. The $21^{\text {st }}$ century in India also has noticed obesity touching the epidemic proportion, with morbid obesity affecting $5 \%$ of the its entire population ${ }^{[5]}$. This study tries to explore the prevalence and various risk factors, which are the leading causes of overweight and obesity among women in a slum of Mumbai. 


\section{Materials And Methods}

Cross sectional community based study design with quantitative method was used to study the prevalence and factors influencing the overweight and obesity in women in a slum of Mumbai. The study was done during the period from March, 2013 to March, 2014 and it was conducted in a slum of Bandra East in Mumbai. The area of this slum spreads to around 28,328 square meters $(0.028$ sq.km). It had approximately 70,000 population. All females 18 years and above were selected for the study. 126 respondents were selected for the interview. There are 10,000 households in this slum. Approximately there are 13 major passages called as 'gullies' inside the slum, each having a distinct name. So in each passage there are approximately 770 households. By simple random sampling procedure, 6 passages were randomly selected. 21 households were decided to be taken from each of these 6 passages. Then, using systematic random sampling, every $36^{\text {th }}$ house was selected for the interview, till 21 females were achieved from each passage. Data collection was done by face to face interview using a pretested, semi-structured interview schedule written in English and translated verbatim into Hindi. Physical measurements such a waist and hip circumference were taken. Body Mass Index (BMI) and waist hip ratio (WHR) were calculated. Informed consent was taken and confidentiality was maintained for all records.

Data were collected regarding various parameters and factors leading to obesity, including sociodemographic details. The study data were collected with the assistance of a community health worker in the program who lived in the community and was respected and well known in the area. The slum in the study area was a new area to be included in the community program if the community were willing. Previous reports of the program had shown increasing incidence of obesity, cardiovascular problems and diabetes in other slum populations. The community health program is a comprehensive program including health education and lifestyle interventions. The community program has been involved in actively promoting healthy life style specially regarding diet and physical exercise. The health workers are also trained to monitor weights, abdominal circumference, blood pressure and blood sugar in the community. They are aware of the complications of obesity and these are being referred and followed up in the weekly clinics of the centre.

\section{Results}

The study is based on data collected from 126 female participants. Regarding the sociodemographic data, 35 (27.8\%) of the women were uneducated and approximately one third, 45 (35.7\%), had studied till the primary level, and $46(37 \%)$ were educated up to the secondary level . Around half of the respondents, 65 $(51.6 \%)$, were in the age group of 30-49 years of age. $38(30.2 \%)$ and $23(18.3 \%)$ of the respondents were in the age group of 18-29 years and 50 years and above respectively. The majority of the respondents were married and all were Muslim by religion.

Almost all of the respondents were non-vegetarian, 102(96.8\%). Around $116(92.1 \%)$ of the population did not partake in physical exercise. The employment status of the respondent shows that $90.5 \%$ of them were unemployed.

Almost one third of the respondents $(32.5 \%)$ had a BMI within the range $25.0-29.9$ and were classified as overweight. While $20.6 \%$ and $6.3 \%$ of the respondents had a higher BMI and were classified as obese class I and obese class II respectively. This showed that the incidence of overweight and obesity was very high $(59.4 \%)$ in the study area.

According to waist-hip ratio (WHR), 91 (72.2\%) of the respondents had abdominal obesity. From the waist circumference measurement, it was found that $72(57.1 \%)$ of the respondents had abdominal obesity and according to BMI calculation, 58.7\% the respondents were in the category of overweight and obese.

A relationship was found between employment status and obesity that is statistically significant at the 5 $\%$ level $(\mathrm{p}=0.027)$. The unemployed respondents had a higher incidence of obesity. It was also found that $92.1 \%$ of the women never perform any kind of physical exercise other than household activities of these three fourth of the subjects had abdominal obesity (WHR). The relationship between obesity and the physical exercise is statistically significant at the $5 \%$ level $(\mathrm{p}=0.027)$. The relationship between non-vegetarian diet and obesity is statistically significant at the $5 \%$ level $(\mathrm{p}=0.005)$. The type of oil used for cooking was mostly palm oil, which contains highly saturated fat and beside this, the cheaper variety of beef was consumed containing very high amount of saturated fat.

\section{Discussions}

There was high incidence of overweight (32.5\%) and obesity class I (20.6\%) and class II (6.3\%) in the studied slum population of women. Abdominal obesity was found in $57.1 \%$ of the respondents. This high prevalence of overweight and obesity could be attributed to the non-vegetarian diet consumed. A similar study, which was done among women in a slum of Chennai, India, showed that the incidence of overweight and obesity was $29 \%$ and $17 \%$ respectively ${ }^{[6]}$. The current study, had a higher prevalence of overweight and obesity. 
Other findings in this study were that, lack of physical activity and unemployed status were associated with obesity. The notion of more than $90 \%$ of the women was that, physical exercise like walking, jogging, skipping etc., are not so important for reducing overweight and obesity, as they feel that the household activities like, cooking, washing clothes and cleaning etc., involves lots of physical stamina and is equivalent to any other physical exercise. Besides, majority of the women in this slum were unemployed, which limits their mobility. This study was consistent with another study done in Delhi, where it showed that the prevalence of obesity is more common in females who had lighter physical activity ${ }^{[7]}$.

\section{Conclusion}

The prevalence of overweight and obesity was found to be very high in the study area. According to waist circumference measurement, $57.1 \%$ of the respondents have abdominal obesity and according to BMI calculation, $58.7 \%$ of the respondents are obese. The paradox of obesity in the poverty of slums was explained by the various associated factors like unhealthy nutritional practices, lack of physical exercise and unemployment. Interventions were planned to obtain weight reduction and control of complications, leading to a better quality of life for the participants of our study.

\section{Acknowledgment}

The authors wish to thank Navjeet Community Health Centre staff of the Bandra Holy Family Hospital and especially Community Health Worker, Naseema Khan, for their assistance in the study. We also acknowledge and thank Adolf Tragler, MSW and Mahesh Nath Singh, Phd for their guidance.

TABLE-1

Frequency distribution of characteristics

\begin{tabular}{|c|c|c|}
\hline Characteristics & $\begin{array}{c}\text { No. of respondent } \\
(\mathbf{n = 1 2 6})\end{array}$ & Percent \\
\hline Non-vegetarian & 122 & 96.8 \\
\hline Yes & 4 & 3.2 \\
\hline No & 10 & 7.9 \\
\hline Physical exercise & 116 & 92.1 \\
\hline Yes & \multicolumn{2}{|}{} \\
\hline No & 12 & 9.5 \\
\hline Employment status of the respondent & 90.5 \\
\hline Employed & 114 & \\
\hline Unemployed & & \\
\hline
\end{tabular}

TABLE -2

Body Mass Index (BMI) frequency

\begin{tabular}{|l|c|c|}
\hline \multicolumn{1}{|c|}{ Body Mass Index (BMI) } & $\begin{array}{c}\text { No. of } \\
\text { respondent } \\
(\mathbf{n = 1 2 6})\end{array}$ & Percent \\
\hline Underweight $(<18.5)$ & 9 & 7.1 \\
\hline Normal (18.5 - 24.9) & 41 & 32.5 \\
\hline Overweight (25.0 - 29.9) & 41 & 32.5 \\
\hline Obese class I (30.0 - 34.9) & 26 & 20.6 \\
\hline Obese class II (35.0 - 39.9) & 8 & 6.3 \\
\hline Obese class III (40 and above) & 1 & .8 \\
\hline Total & 126 & 100.0 \\
\hline
\end{tabular}

TABLE-3

Anthropometric characteristics of studied subjects

\begin{tabular}{|l|c|c|}
\hline \multicolumn{2}{|l|}{ No. of respondent (n=126) } & Percent \\
\hline Waist-hip ratio (WHR) & 35 & 27.8 \\
\hline Abdominal obesity absent (up to 0.80) & 91 & 72.2 \\
\hline Abdominal obesity present(0.81and above) & \multicolumn{2}{|c|}{} \\
\hline Waist circumference (cm) & 54 & 42.9 \\
\hline Abdominal obesity absent (up to 80 cm) & 72 & 57.1 \\
\hline Abdominal obesity present(80.1cm and above) & 52 & 41.3 \\
\hline Body Mass Index (BMI) & 74 & 58.7 \\
\hline Non overweight and obese (<25.0) & & 72 \\
\hline Overweight and obese (25.0 and above ) & & 5 \\
\hline
\end{tabular}


TABLE-4

Employment status, Physical exercise, non-vegetarian and abdominal obesity cross tabulation

\begin{tabular}{|c|c|c|c|}
\hline \multicolumn{4}{|c|}{ Body Mass Index ( BMI) } \\
\hline & Non obese $(<25.0)$ & Obese( 25.0 and above ) & P value \\
\hline \multicolumn{4}{|c|}{ Employment status of the respondent } \\
\hline Employed & $9(75.0 \%)$ & $3(25.0 \%)$ & \multirow[t]{2}{*}{0.027} \\
\hline Unemployed & $43(37.7 \%)$ & $71(62.3 \%)$ & \\
\hline \multicolumn{4}{|c|}{ Waist-hip ratio (WHR) } \\
\hline & $\begin{array}{c}\text { Abdominal obesity absent } \\
\text { (up to 0.80) }\end{array}$ & $\begin{array}{c}\text { Abdominal obesity present } \\
(0.81 \text { and above })\end{array}$ & P value \\
\hline \multicolumn{4}{|c|}{ Respondents performing physical exercise } \\
\hline Yes & $6(60.0 \%)$ & $4(40.0 \%)$ & \multirow[t]{2}{*}{0.027} \\
\hline No & $29(25.0 \%)$ & $87(75.0 \%)$ & \\
\hline \multicolumn{4}{|l|}{ Non-vegetarian } \\
\hline Yes & $31(25.4 \%)$ & $91(74.6 \%)$ & \multirow[t]{2}{*}{0.005} \\
\hline No & $4(100.0 \%)$ & $0(0.0 \%)$ & \\
\hline
\end{tabular}

\section{References}

[1] World Health Organization (WHO). The Asia-Pacific perspective: redefining obesity and its treatment, 2000. http://www.wpro.who.int/nutrition/documents/docs/Redefiningobesity.pdf. Accessed on February 17, 2013.

[2] World Health Organization (WHO). Health Transition. http://www.who.int/trade/glossary/story050/en/. Accessed on February 17, 2013.

[3] World Health Organization (WHO). Obesity and Overweight, fact sheet, May 2012. http://www.who.int/mediacentre/factsheets/fs311/en/. Accessed on February 9, 2013.

[4] G.A. Stevens, G. M. Singh, Y. Lu, G. Danaei, J.K. Lin, M.M. Finucane, A.N. Bahalim, R.K. McIntire, H.R. Gutierrez, M. Cowan, C.J. Paciorek, F. Farzadfar, L. Riley and M. Ezzati. National, regional and global trends in adult overweight and obesity. Population Health Metrics, 2012, 10:22.

[5] P.K. Agrawal. Emerging obesity in Northern Indian States: a serious threat for health. IUSSP conference, Bangkok, 2002, 10-12.

[6] R. Anuradha, G. Ravvarman and T. Jain. The prevalence of overweight and obesity among women in an urban slum of Chennai. Journal of Clinical and Diagnostic Research, 5(5), 2001, 957-960.

[7] N. Gopinath, S.L. Chadha, P. Jain, S. Shekhawat and R. Tandon. An epidemiological study of obesity in adults in the urban population of Delhi. The Journal of the Association of Physicians of India, 42(3), 1994, 212-215. 